\title{
The Administration of Cast Vote Records in U.S. States*
}

\author{
Shiro Kuriwaki ${ }^{\dagger}$
}

December 30, 2020

\begin{abstract}
I survey the state of election administration surrounding cast vote records in U.S. states. To study how states currently collect, preserve, and protect cast vote records, I made customized inquiries to election officers of all 50 states and D.C. The investigation shows how the administration of cast vote records is intricately related to other aspects of election administration: post-election audits, the interpretation of sometimes ambiguous regulations around the preservation of voted ballots and cast vote records, and the debate surrounding open records requests. I conclude with what the recently matured movement for common data formats entails for these issues surrounding cast vote records.
\end{abstract}

* Technical report, prepared for presentation at the 2019 Election Sciences, Reform and Administration Conference. I thank the state election officials who responded to my inquiry, as well as David Kimball, Michael Morse, Jennifer Morrell for helpful suggestions. These are early findings; comments are welcome.

$\dagger$ Ph.D. Candidate, Department of Government and Institute of Quantitative Social Science, Harvard University (kuriwaki@g.harvard.edu, http://www. shirokuriwaki.com). 
Cast vote records are a byproduct of recent voting technology that has widespread academic and administrative uses, but the landscape of how states collect, administer, and preserve cast vote records (CVRs) remain unclear. In an academic study of ticket splitting, Kuriwaki (2020) employed cast vote records from the entire state of South Carolina, while Morse (2021) used cast vote records from Florida to study the bipartisan support for a constitutional amendment. The data collection involved in that study was tractable because South Carolina's state election commission had been collecting CVRs from each of the 46 counties in the state since 2010. Most other states, however, do not appear to collect these records and instead collect tallies (sums) of votes by office. What is the role of cast vote records, if any, in the administration of modern elections?

\section{Collection of CVRs}

In 2019 I first sent customized e-mail inquiries to state election directors, public information officers, and other official contacts in all 50 states and DC, inquiring whether their office received cast vote records from individual offices. Figure 1 shows a summary of results. As of July 25 2019, I received responses from 41 states.

Seven states - South Carolina, Rhode Island, Maryland, Colorado, Georgia, New Mexico, and Hawaii, appear to have collected CVRs in the 2018 election cycle. Maryland has conducted a $100 \%$ post-election audit since 2016 aided by scanning and OCR technology by the company Clear Ballot. ${ }^{1}$ As a consequence, the Maryland Board of Elections retains CVRs from all of its counties in the 2016 and 2018 general elections (Agadjanian and Robinson 2019). Rhode Island and Colorado use different voting methods (in-person voting of paper ballots and primarily statewide vote-bymail, respectively), but share the common factor of conducting Risk-Limiting Audits (RLA) or preparing for one. A RLA is a type of post-election audit that samples vote records for evidence that the outcome is correct. ${ }^{2}$ Therefore, one condition of implementing a RLA is that jurisdictions must have access to all ballots from the state. Finally, Hawaii and New Mexico seem to be two states (among those that have responded) that collect cast vote records in a central counting (canvasing) facility.

1 Clear Ballot Press Release, 2016. "The Maryland State Administrator of Elections and Clear Ballot Will Conduct the Nations First Ever 100 Percent Statewide Post-Election Audit."

2 For a broad introduction, see http://bit. ly/2MeWSAV; for the statistical theory behind the RLA, see Stark (2008). 
Figure 1: State Administration of Cast Vote Records

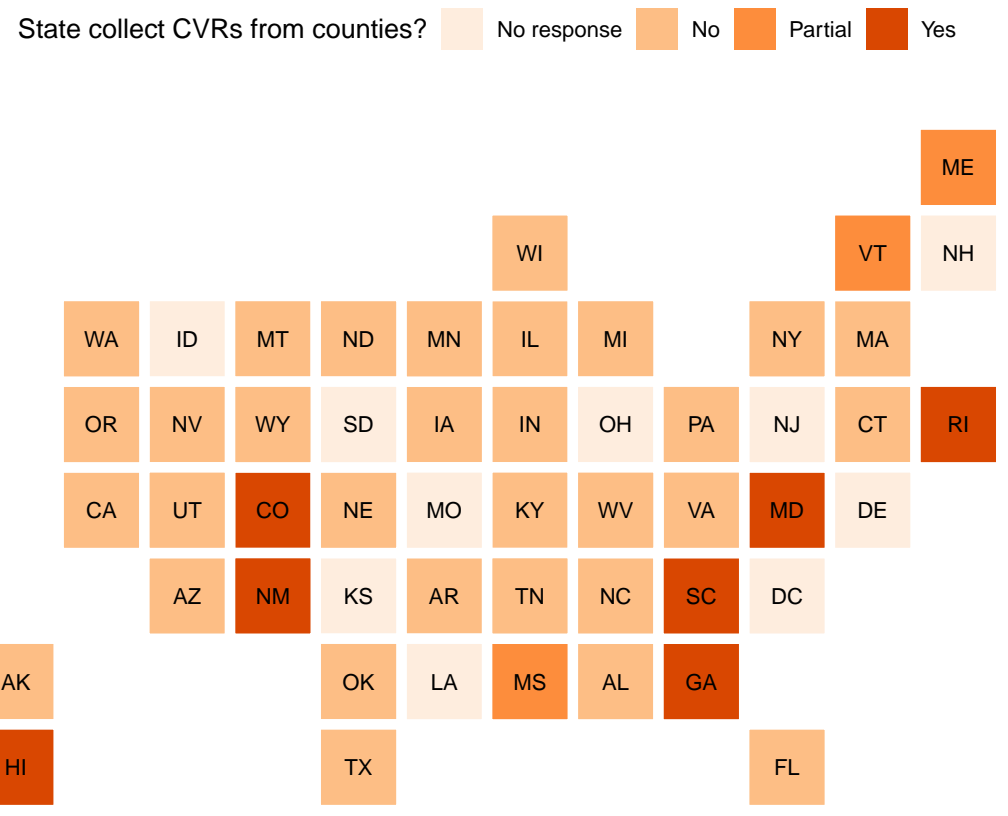

Note: Coloring indicates whether cast vote records are sent to the central election center, based on responses to the author as of July 25, 2019. See main text for details.

Mississippi, Vermont, and Maine are three states that partially collect CVRs, and their practices are instructive. Mississippi collects audit logs (not as easily accessible as a CVR is) from a "random sampling of precincts" for their post-election audit. The Vermont Secretary of State audits the ballot images generated from six towns in the general elections of 2014, 2016, and 2018 (Hansen 2015). On the other hand, the Maine Elections Board started collecting CVRs in 2018 only for the offices elected by Ranked Choice Voting.

Most states that responded to my inquiry reported that cast vote records never leave the county. These include the states of Alabama, California, Illinois, Indiana, Florida, Kentucky, Minnesota, Montana, Nebraska, Nevada, New York, Oregon, Tennessee, Texas, Utah, Wisconsin, Wyoming. In fact, some states reported operating voting machines or vote marking machines that make it impossible to store the cast vote records all together. In Massachusetts, AutoMARK tabulators that can take an image are programmed by the state not to do so. Connecticut uses the Inspire Ballot Marking System, in which cannot store images. In most cases, 
counties in a single state use different vendor's voting machines, which is a technical impediment for the county to centralize CVRs. ${ }^{3}$ In these states, collecting CVRs is a county by county process.

In these states where cast vote record collection is not centralized, research on voting behavior becomes more time intensive but by no means impossible. Gerber and Lewis (2004) collect and re-create CVRs from Los Angeles county in 1992, Herron and Lewis (2007) collect CVRs from 10 Florida counties in 2000, Bafumi et al. (2012) collect CVRs from 14 South Carolina counties in the 2010 Democratic primary, and Morse (2021) has collected CVRs from around 80 percent of Florida counties in 2018. County and large city governments also post their CVRs, for example the City and County of San Francisco and Dane County, Wisconsin.

One qualification to these findings is that my inquiry may have been ambiguous to some officials because it asked about "ballot image logs and cast vote records" at the same time and state administrators may have had different definitions of these terms. An officer at the New Mexico Bureau of Elections, for example, initially responded that electronic records were not centralized by the state. However, upon further clarification, it was made clear that while scans of ballots (what some people mean by ballot images) are not taken, counties do upload the electronic record of each vote at the individual level to the secretary of state, and the state performs a canvas of the votes in statewide offices. This ambiguity in terminology has several consequences for administration, which I turn to next.

\section{Preservation}

If counties retain cast vote records in most states, how are these preserved? The answer turns out to be fairly variegated, partly because of the ambiguity of state election codes and whether CVRs qualify as "voted ballots."

A common rule shared across multiple state legislation is that voted ballots should be preserved for up to 22 months, as styled on 52 USC $\S 20701 .^{4}$ New York's statute is one of many pieces of such legislation ${ }^{5}$ :

"Voted ballots shall be preserved for two years after such election and

3 The voting machines counties use can be found in https://www.verifiedvoting.org/verifier. In some states, even a single county can use different voting methods. See for example the distribution in Minnesota at http://bit. ly/32iGwfy.

4 See http://bit. ly/2XUyHwV.

5 New York Election Law, Section 3-222. Also see, for example, Iowa Code Section 50.19 
the packages thereof may be opened and the contents examined only upon order of a court or judge of competent jurisdiction, or by direction of such committee of the senate and assembly if the ballots relate to the election under investigation by such committee, and at the expiration of such time, such ballots may be disposed of at the discretion of the officer or board having charge of them."

Adding "voted" in references to ballots makes the first-order distinction between completed ballots and blank ballots that have been printed but not used. This distinction clears the way for states to dispose of these blank ballots. But whether electronic CVRs fall under voted ballots is unclear. On the one hand, CVRs are only copies of the original ballot. If the intent of the preservation law is to prevent the tampering of ballots, then ultimately only the original ballot is of interest. DRE machines, however, especially those before the Help America Vote Act (HAVA) with a paper trail, muddy the distinction. And on the other hand, if the intent of the preservation laws also include preserving the integrity of the ballot and finality of election results, CVRs may be effectively equivalent to voted ballots. More precisely, CVRs under this interpretation could be considered equivalent to the original to the extent that they can be used as evidence in court to dispute election results.

A few states have grappled with this question and reached explicit conclusions. The California elections division interprets digital ballot images to be covered under the 22 month preservation rule. ${ }^{6}$ The North Carolina statute on the preservation of ballots refers explicitly to "[v]oted ballots and paper and electronic records of individual voted ballots" 7 . The Colorado statute clarifies that "Ballot includes any digital image or electronic representation of votes cast." And, unlike the first two states, Colorado designates the cast vote records as open record. Individual counties, including Miami-Dade, Florida (from the 2004 election) and also Dane, Wisconsin (from 2016) share these records publicly.

Yet in most states, the distinction is much less clear. For example the Nevada statute refers to "the voted ballots and records printed on paper of voted ballots," not referencing cast vote records stored digitally on memory drives. ${ }^{8}$ In fact, this matter of interpretation of voted ballots was the subject of discussion in a recent

6 Personal communication with Assistant Chief of Election Division. Also see California Elections Code sections $\S 17,17301-17306$, especially 17303 (b)(2) and 17304 (b)(2).

7 North Carolina General Statutes $§ 163 \mathrm{~A}$ - 1105(e).

8 See Nevada Revised Statues 293.391, subsection 5. 
case brought to New York state's court of last resort (see next section on Kosmider $v$. Whitney for details). And, it appeared that some state officials in my e-mail correspondence were not immediately clear on whether CVRs were subject to preservation rules. An expert on RLAs and frequent consultant, also observes from her experience that unless a state is conducting or considering conducting a RLA, officials tend to be unfamiliar with what a CVR actually is (Jennifer Morrell, personal communication).

\section{Confidentiality}

The variation interpretations of CVRs ultimately affect how confidential they are for research. The main reason jurisdictions provide when insulating CVRs from public records requests often come down on the notion that CVRs can be de-anonymized. Redaction policies are a promising middle-ground that can allow transparency while guaranteeing anonymity.

On June 13, 2019, the New York Court of Appeals (the highest court in the state) in Kosmider v. Whitney (N.Y. 2019) ruled in a 4-3 decision that the county Essex was justified in denying a Freedom of Information Law (FOIL) request to turn over CVRs from a 2015 election. In so doing, it reversed the decisions of two lower courts which had originally ruled that the preservation statute did not preclude the FOIL of CVRs.

Although the ruling largely revolved around the interpretation of the preservation statute as discussed in the previous section, a separate consideration that animated the oral arguments was the confidentiality of voter's identity. The relevant parts of the argument are re-produced in the Appendix. Essex county argued that in some rare cases, the identity of an individual CVR could be revealed in small electoral districts, giving an example of a handful of voters voting in a primary in a small electoral district that could then be cross-referenced in the voter file. Moreover, if this voter turned out pivotal in a contest, disclosures may lead the public to litigate election results long after the election was certified.

Rulings in other state courts are more explicit in their concerns for confidentiality. In 2017, a superior court judge in Pima County, Arizona ruled that ballot images to be treated the same as physical ballots, a case that led the state legisla- 
tures to write in the protection of electronic images into law. ${ }^{9}$ In contrast, a district court in Jefferson County, Colorado found earlier that, unlike the New York decision, electronic records were subject to Colorado's Open Request Laws. ${ }^{10}$ In sum, confidentiality concerns affect whether states make CVRs available for researchers.

The Risk-Limiting Audit Representative Group in Colorado has addressed this question in their recent report (McCarthy et al. 2018). Unlike some litigation, the group attempted to achieve transparency of the voting tabulation without compromising confidentiality. The report notes that in Colorado there also exist small pockets of voters who are in rare combinations of electoral districts that would, due to their rarity, would expose their CVRs to be de-anonymized. The group recommended redaction of the down ballot offices that are at risk of deanonymization. Because the records considered open record, the local clerk can redact portions of the CVR that would compromise voter anonymity.

\section{The Future of Cast Vote Records}

The survey of election administration and controversies surrounding open records laws are indicative of how jurisdictions are only beginning to reach resolutions on how to deal with cast vote records. In addition to their contribution to academic research, CVRs hold large potential to improve the transparency of elections and are integral to the discussion about post-election audits. That said, the withinand across-state variation in equipment and administration complicate a systematic assessment of the situation.

Amidst such confusion, the ongoing movement to provide a common data format for election data becomes especially important. Since the early 2000s, the National Institute for Standards and Technology (NIST) has devised a set of unifying formats and languages to refer to and organize all election data that goes in and out of the election management system. This group has recently published a report on these standards, and is encouraging states and vendors to make their systems compatible

9 See "Pima County Judge Rules In Favor Of Voter Privacy, Ballot Images Same As Ballots", Arizona Daily Independent, May 31, 2017. http://bit.ly/32gUnmv. Senate Bill 1094 in the 2017 session was passed to add a section, 16-625, titled "Relating to Tally and Returns" to read: "The officer in charge of elections shall ensure that electronic data from and electronic or digital images of ballots are protected from physical and electronic access, including unauthorized copying or transfer, and that all security measures are at least as protective as those prescribed for paper ballots."

10 Case brought by Marilyn Marks, Case No. 2011-CV-3576, (Jefferson Cnty. Dist. Ct.). 
to this language (National Institute of Standards and Technology 2020; Dziurlaj 2020). A common data format allows, for example, voting tabulators from different vendors to contribute CVRs to a statewide database in a common publicly available standard. This would reduce the transaction costs for states who want to conduct more auditing but whose counties currently use multiple machines. I would argue that the responsible collection and scalable organization of available cast vote records (through these common data formats, for example) are important considerations for researchers using cast vote records. 


\section{References}

Agadjanian, Alexander and Jonathan Robinson (2019). "Ground Truth Validation of Survey Estimates of Split-Ticket Voting with Cast Vote Records". URL: http: //bit. ly/2XBKSKZ.

Bafumi, Joseph, Michael C. Herron, Seth J. Hill, and Jeffrey B. Lewis (2012). "Alvin Greene? Who? How Did He Win the United States Senate Nomination in South Carolina?" Election Law Journal 11 (4), pp. 358-379. DOI: 10.1089/elj . 2011. 0137.

Dziurlaj, John (2020). Common Data Formats and the Entity-Relational Model. URL: https : / / github . com / HiltonRoscoe / CDFPrototype / blob / master / relational / relational.md.

Gerber, Elisabeth R. and Jeffrey B. Lewis (2004). "Beyond the Median: Voter Preferences, District Heterogeneity, and Political Representation". Journal of Political Economy 112 (6), pp. 1364-1383. DOI: 10.1086/424737.

Hansen, Jeremy A (2015). "Ballot-Level Observations about Vermont's 2014 General Election". New England Journal of Political Science 8 (2), pp. 186-217.

Herron, Michael C. and Jeffrey B. Lewis (2007). "Did Ralph Nader Spoil a Gore presidency? A Ballot-level Study of Green and Reform Party Voters in the 2000 Presidential Election". Quarterly Journal of Political Science 2 (3), pp. 205-226. DOI: $10.1561 / 100.00005039$.

Kuriwaki, Shiro (2020). "Ticket Splitting in a Nationalized Era". DOI: 10.31235/ osf.io/bvgz3. URL: http://doi.org/10.31235/osf.io/bvgz3.

McCarthy, John, Neal McBurnett, Harvie Branscomb, Ron Rivest, and Philip Stark (2018). Preserving Anonymity of Cast Vote Record. Tech. rep., pp. 1-11. URL: http://bit. ly/2LcuCOQ.

Morse, Michael (2021). "The Future Of Felon Disenfranchisement Reform: How Partisanship And Poverty Shape The Restoration Of Voting Rights In Florida". California Law Review 109.

National Institute of Standards and Technology (2020). Special Publication 1500103, Cast Vote Records Common Data Format Specification Version 1. Tech. rep. National Institute of Standards and Technology. DOI: 10.6028/NIST . SP . 1500 103.

Stark, Philip B. (2008). "Conservative Statistical Post-Election Audits". Annals of Applied Statistics 2 (2), pp. 550-581. DOI: 10.1214/08-A0AS161. 


\title{
Appendix A: Oral Argument Excerpts, Kosmider v. Whitney
}

\author{
The following are relevant exercepts from Oral Arguments in the Court of Appeals, \\ Kosmider $v$. Whitney. The full transcript can be viewed at http://bit. ly/2Hc60qK.
}

\section{A.1 Excerpts from Daniel T. Manning, Essex County Attorney}

$\cdots$

MR. MANNING: But getting back to my argument, in our opinion, voted ballots and copies of voted ballots, whether it be a paper copy or an electronic copy are all one in the same.

JUDGE STEIN: Well - -

JUDGE FAHEY: Well, is there - - is there anything in the law that defines "voted ballot"?

MR. MANNING: No, voted ballot is -- there's no -- definition, however, there's no preclusion. The first Section of 3-222(1), relates only to removable memory cards and their sealing and reuse. That's it. Then you take the next lock - -

JUDGE STEIN: But didn't Subsection 2 previously refer to write-in ballots, and isn't there some legislative history that - - that the reason why it was changed to voted ballots, was to save the cost of storing unused ballots? Would -- do you agree with that?

MR. MANNING: I know that it - - there was - - the change was - - there was a change in that section from voted ballots to - -

JUDGE STEIN: And if -- if that's true--

MR. MANNING: -- from write-in to --

JUDGE STEIN: - - then how does that lead us to a clear legislative intent to define voted ballots as meaning both paper ballots as well as these electronic versions?

MR. MANNING: I would argue that the clear reading of "voted ballots" would include a copy of the voted ballot, which is a paper copy, and an electronic copy, which is also just a copy.

JUDGE STEIN: Well, but isn't that the point is that - - that under - - under FOIL, we have to show a clear legislative intent. And that this is - - that there is - that there's some ambiguity here, so how can we translate that into a clear legislative intent?

For example, it seems to me that -- the question, other than the question of whether these are voted ballots or not, which is the ultimate question, but one step before that is, what is the purpose of the preservation of -. what's the purpose of these rules? Is it to prevent tampering? or is it for confidentiality purposes? Because I think that depending upon how you come out on that question, you get a different answer to whether it's FOIL-able or not.

And you know, it - - the -- the history is, is that we had paper ballots, and that if somebody gets ahold of them, they can easily be tampered with. Whereas, once something is preserved on a hard drive somewhere, then giving out images of it doesn't affect the original.

MR. MANNING: I would argue that even though it's stored on electric - - on a hard drive, electronically, that that could be tampered with at any time.

$\ldots$

MR. MANNING: Okay. I'd - - I'd like to skip just quickly and I'll - - I will get to that, but to address the intent question, since that's very important. If you look at the statute -- the Election Law as a whole, and the statute that come before it, 9-200s through -- there are all these procedure -- all these instances where either the candidate or a chairman or even a lay person has an opportunity to attend the canvass, attend the there-percent audit, attend the canvass of the absentee ballots, and the re-canvass, and also the certification.

16-112 of the Election Law also permits through the Supreme Court and an order, where there's a judge who makes a decision whether this should be given out or not, the ability to take a look at these ballots.

JUDGE FAHEY: I see.

MR. MANNING: However, to allow FOIL, -- just a blanket FOIL request access to these, what are essentially copies, in my opinion, of voted ballots - They are not--which 
could be tampered with. I - - I believe it --

JUDGE FAHEY: Well, let's assume it -- let's assume, but there'd be copies of a canvass. You still have the originals.

MR. MANNING: We still have the originals.

JUDGE FAHEY: But then it would turn into a question of which was true and which wasn't.

MR. MANNING: Absolutely. Either one could be tampered with. The originals could be tampered with. You know, there are all sorts of strange things that - -

JUDGE RIVERA: Well, thats why you have the redundancies. And that - - that certainly was a question when you went to this kind of -- digitized voting. You have the redundancies because you have the original ballot. You're right; it could be tampered with. The whole point is to try and secure it, as Judge Stein was asking about that other question, secure it, so they don't get opened and they don't get tampered with.

Whereas, the digitized, if - - if it makes it to that server without having been tampered with, because that's possible too, then you'd have to hack into the whole system, so that's why you build in a bunch of redundancies. I get that.

But - - I'm not really clear how a copy of something on your server is the voted ballot. Isn't a voted ballot being - - that material that someone voted on.

MR. MANNING: Clearly, what if - - what if someone asks for a copy of a voted ballot? It's the same, in my opinion, the paper -.

JUDGE RIVERA: But that's not what the section says. It doesn't say voted ballots and all copies.

MR. MANNING: But I - - I think it's implied. If you can't - - if you can only examine --

JUDGE RIVERA: What - - what allows one to imply from this section that voted ballots can be read as voted ballots and all copies?

MR. MANNING: The-- it--it goes onto say that they can only be examined. So you get to look at the voted ballot under Section 3-222. You don't get to take it home. You get --don't get to--to take- - take a picture of it.

JUDGE RIVERA: - - avoids tampering, sure.

MR. MANNING: Right. And so a logical extension of that is you can't give someone a copy of that voted ballot.
And I - - tampering is one reason, I believe, in -- in the legislative history - -

JUDGE RIVERA: After two years you can sell it, right?

MR. MANNING: You could sell it and you could discard of it.

JUDGE WILSON: Well, I wanted - - I wanted to ask you about that. What is it you can sell? Is it the envelopes or is it the ballots?

MR. MANNING: The way I read the law, I think you can sell the ballots - -

JUDGE WILSON: Do you know if - has anyone ever sold - -

MR. MANNING: - - but I don't know if anyone's ever sold them. I think they're usually disposed of or destroyed.

JUDGE WILSON: Do you have any idea what the legislature was thinking about when they authorized the sale of something?

MR. MANNING: No, I do not, and I don't--I don't think it's a good idea, but it's not my call.

JUDGE RIVERA: Well, the suggestion is that it might be used for research and you want the original ballots.

MR. MANNING: Right, right, but you could in small primaries where there are one --

JUDGE RIVERA: It may be very well be now that you have the electronic copies, that most researchers would be happy not to pay for the printing costs upfront, and just send it - - send the copies digitally.

MR. MANNING: Right. It is our position on the voted ballot - - and - - and any copy of that voted ballot, whether it be electronic, paper copy, can't be disseminated - - can't be examined without a court order. If - - what would happen if the paper ballots would --

CHIEF JUDGE DIFIORE: Are you saying we're not in the FOIL world?

MR. MANNING: I'm saying we're not in the FOIL world.

CHIEF JUDGE DIFIORE: We're in Election Law

MR. MANNING: I'm saying the statute -- I don't mean to interrupt; I'm sorry.

CHIEF JUDGE DIFIORE: Okay. 


\section{A.2 Excerpts from James Walsh, Attorney for Appellant, Allison McGahay}

MR.WALSH: And--and what will happen is, you'll get into the end of November, and the board of elections will certify one winner, and now you've got a certified winner, that is going to be presented as that's the -.

JUDGE FAHEY: So - - a party could conceivably have blown their opportunity to go into court under the Election Law to challenge the election, but could then get the information regarding the election under FOIL. But let's say that's true. Let's just speculate. So that's true; that happens. Somebody else is in the seat. You lose. Tough luck, you blew the - - it happens all the time in the Election Law. You blew -- you blew the statute of limitations; you don't get it.

So then somebody brings a FOIL action, and they say, well, I might be not able to challenge his seating, but I want everybody to know they didn't win the election. I won the election, and here's these three ballots, and one was mismarked or some - - it - - it happens, particularly in minor party cases.

Why is that wrong? Why shouldn't we allow that?

MR. WALSH: It erodes the public confidence in our elections, and it erodes the public confidence in government.

JUDGE FAHEY: Well, here's -- here's - - here's a rule. Truth doesn't erode anything. It's mistruths that that erode things. So if the truth is that -- that the election is undermined by a fact that's in contest, then that fact should be out there. And the next time, whoever's running, and those two people will have to deal with it, whatever it is.

But I thought the integrity of the ballot issue was the more compelling issue from your point of view, which is that if - - if access to these things are being given out before, as Mr. Ferebee said, before the number of - - in a challenged election, the number of recounts are complete, whether they're absentee, special elections, military ballots, or in the case of the three percent that you're looking at, if the elections say within a hundred votes, then you're doing another recount.

And they take long enough so that you could be within the statute of limitations and also complete under FOIL as Judge Garcia and Judge Feinman have pointed out.

So that creates an integrity of the ballot issue, and that's why I'm wondering, shouldn't that process be always completed before you can FOIL something? That's what I want you to drive at.

MR. WALSH: I -- I think you have to, Your Honor, and I think you have to have that completed - -
JUDGE FAHEY: But why? Why - - why would the integrity of the ballot be undermined in that position - - in that situation?

MR. WALSH: Your Honor, it's not only an integrity of the ballot, but it's the secrecy of the ballot. It's the secrecy of the ballot and -- and I'll come back to --

JUDGE FAHEY: Well, I - - I consider those things the same thing.

MR. WALSH: Well, so if -- to - - to use the example that this isn't just for Essex County, this is for every place. So in Hamilton County, where you have forty people in -in the Integrity Party, and you've got one person in one $E D$, and if they show up and vote, you know how they voted. If - .

JUDGE STEIN: But if -- if the board of elections can sell these ballots at some point, then at some point, where - whether it's - - I mean, and the time frames have changed throughout the years, throughout this legislative history. It was six months at some point. But at some point, you can sell it. Then what is - - I don't understand what the secrecy means. Once it's out, it's out, and then everybody knows how you voted, even if it's two years later.

MR. WALSH: Okay.

JUDGE STEIN: So - -

MR. WALSH: But -- but Your Honor, I would say that if we look at the headlines today, we see that - - that the - the New York Times as well as the Post yesterday, Governor Cuomo is upset with the New York City Board of Elections, for releasing data that's personal data, "an unwarranted invasion into personal privacy", which is one of those exclusions under FOIL. That just the data, the name, the enrollment, where they live, and what their date of birth is, that - - that the Governor is saying that's - - that's personal information; it shouldn't be released. Now we can go in and get the -- the vote.

JUDGE STEIN: Was that argued here? Was that argued here or was that given as a basis for denying the FOIL request?

MR. WALSH: I -- I don't believe that was given as a basis for denying, Your Honor. I think what the basis for the denial was, that this an Election Law matter, and as an Election Law matter, the -- the Article 3-222(1) and (2) says, you can't have access to that. So I - - I think I

JUDGE RIVERA: I - - I'm still - - I'm sorry. I still don't understand this argument that somehow turning over the 
digital versions of the ballot -- that digital copies of that ballot will reveal what any particular individual's vote was. Right, when they're scanned, they're randomized anyway.

MR. WALSH: But Your Honor, the ballots have the town and the election district printed on them. It's printed there.

JUDGE RIVERA: Yeah.

MR. WALSH: So in that small party, in the minor party, where there's two people who vote, and they both vote for candidate A, you know how both of those people voted - -

JUDGE RIVERA: I don't -

MR. WALSH: - - or if only one person votes - -

JUDGE RIVERA: I don't understand how the ballot show that they voted for them. Someone else could have voted for them. I - I'm not--

MR. WALSH: Because --

JUDGE RIVERA: You mean, because only two people voted, is that what you mean?

MR. WALSH: - - in that town and in that election district, only two people voted.

JUDGE RIVERA: Only two people voted and there's only two copies, that's their vote. Is that what you mean?

MR. WALSH: Yes, Your Honor.

JUDGE RIVERA: They're the only two who voted?

MR. WALSH: Correct, or -- or if you've got two registered voters and only one shows up and vote, now you know how they voted. And that secrecy is - - is the - - the thing that what - - I think we need to protect.

JUDGE RIVERA: Well, I think as Judge Stein suggested, if you had that kind of a request, with that kind of a district, maybe you have an argument about confidentiality, but that's not the argument that was the basis here.

I just want to ask you one more - - I noticed the red light has gone on, but I'm circling back to a question I had for you before about whether or not other counties actually released them. Are you -- I thought in the record there's an affidavit from Douglas Kellner that - - as far as he knew -- counties do turn it over; Essex is the only one that doesn't.
MR. WALSH: That -- that's not true, Your Honor. In fact, there - - there are - - there - - there's a split decision, because the Committee on Open Government has given the advice that you got to release these. Some commit - - some counties have; other counties haven't. And the reason that - - that - - that's an advisory opinion. That's not law; that's not something that they're required to do.

But I think that the -- the Committee on Open Government has failed to look at that unwarranted invasion of personal privacy. Because you -- you're not just applying to Manhattan or to the Democratic primary in Manhattan. You're talking about places where two people vote, one person votes, four people vote. And if they all go the same way, you know how they all voted.

JUDGE GARCIA: Can you tell a sequence from the copies? If there's five people who voted, and you get what you want under this FOIL request, can you tell 1 through 5 , or you don't know that?

MR. WALSH: You--you--you cannot, Your Honor, because what happens is, that they will jumble the images, and on -but what will happen is, you know which ED in -- in the town, so you -- you will know if - - so if two people vote, and one's in one ED and one's in the other ED, you'll know how they both vote. So again, this isn't something that you really concern about the -- the privacy.

And I-- I want to hit one more thing. That the legislature saw fit to say to election officials, it's a crime if you figure out how somebody voted and you reveal that or you $-$

JUDGE RIVERA: You could redact it, you know.

MR. WALSH: Your Honor?

JUDGE RIVERA: You could redact. You could redact information that might reveal - -

MR. WALSH: You -- well -.

JUDGE RIVERA: - - someone's vote.

MR. WALSH: I - - I - Your Honor, I'm talking - - it -- it's illegal for an election official to reveal how somebody votes. When you're - - when you're - - when you're not looking at the ballots on the machines, we're looking at the absentee ballots, where we're opening those small universes of one or two ballots in one ED, and they all go the same way, well, then you know, because you know who the universe of the people who voted, if they all voted the same way, we know how they voted. It's illegal to reveal how they voted. So the -- the legislature has saw fit to ensure that $A$, you can't reveal it, and if you do, it's a crime. Thank you.

CHIEF JUDGE DIFIORE: Thank you, counsel. Counsel? 


\section{A.3 Excerpts from Daniel Novack, Attorney for Respondent, Bethany Kosmider}

MR. NOVACK: Good afternoon, and happy Law Day.

CHIEF JUDGE DIFIORE: Thank you, sir.

MR. NOVACK: Daniel Novack for respondent Bethany Kosmider. I feel like I'm sensing some confusion from the court on this issue of identifying voters. I have to confess; I'm extremely confused by this. We have to voter roll, and we have certified totals. If there's a town with one person in it, and we know the voter roll, and we know the vote, we can connect them. This information will not provide anything new that isn't already completely public.

Now if there are smaller - -

JUDGE RIVERA: You mean, that any time anyone could ask to see the voter roll?

MR. NOVACK: Correct, and that's not --

JUDGE RIVERA: After the election?
MR. NOVACK: Correct, and that's not disputed here.

So in -- my understanding is in towns where that is a factor, where you have the local, you know, race that maybe draws one or two voters, period, they often times will group up with other districts, so that there's some practical anonymity. FOIL is a flexible law as -as one of the points made here was that redaction is a possibility. These are really extreme scenarios. They're not really contemplated by the statute, certainly not by this statute, nor -- nor by FOIA -- but FOIL, but theyre certainly workable.

What we're looking at here is not that situation. The vast majority of situations don't even resemble this. It's true that some jurisdictions are not releasing this data. Essex County actually released it the year before my client requested it. In 2014, they saw fit to release it; in 2015, they unfortunately denied it. New York City routinely releases this data. 